\title{
LOS COSTES DE LA REPRESIÓN. UNA PARÁFRASIS CON DOS PEQUEÑAS VARIACIONES
}

\author{
Celestino Pardo
}

ESADE

RESUMEN. La progresiva revalorización de factores como el capital y el trabajo ha repercutido negativamente en los costes de las actividades irregulares, ilegales o delictivas, al elevar en términos absolutos el valor de los daños que sufren quienes las soportan y, en consecuencia, las expectativas de beneficios de quienes las realizan.

El crecimiento del riesgo de delinquir o infringir la ley, debido al aumento de las ganancias esperadas, es decir de la tentación para hacerlo, como no podía ser menos, se ha traducido, a su vez, inmediata e inexorablemente, en un incremento de las sanciones y reparaciones que los malhechores han de afrontar y en su caso abonar.

Ahora bien, a medida que aumenta la diferencia entre, por un lado, el beneficio esperado de las conductas irregulares y las penas con que se las amenaza, y, por otro, la retribución de los funcionarios que las aplican, inevitablemente, se eleva también el riesgo de corrupción; y, por tanto, la «tasa de descuento de la arbitrariedad de los Estados» que los mercados y, en general, los ciudadanos, han de soportar (y, en consecuencia, pagar).

A partir del trabajo ya clásico de Stigler-Becker se analizan las distintas variantes organizativas (o políticas represivas) que pueden ensayarse para rebajar el montante de esa tasa. Finalmente se apuntan algunas razones en favor de los sistemas de prevención que Calabressi llamó "específica»; especialmente los que sujetan el ejercicio de actividades potencialmente peligrosas a control o autorización previa.

Palabras clave: análisis económico del Derecho, Calabressi, Stigler, Becker.

ABSTRACT. The ongoing revaluation of factors as capital and work has affected negatively in the costs of irregular, ilegal or delictive activities, because it absolutely increases the amount of damages suffered by those who have to put up with them and so the expectations of benefits of those who commit them.

The growth of the risk of commiting a crime or to break the law (due to the increase of the expected profits) has caused as well an increase of the sanctions and repairs that those braking the law have to face and pay.

However, the more it increases the difference between, on one side, the expected benefit of the misconducts and the costs of their punishments, and, on the other side the payment of the government employees who apply them, the more it raises the corruption risk, and so the «rate of discount of State's arbitrariness", that domestic market and individuals have to put up with.

From the classic studies of Stigler-Becker the different organisation variants are analyzed (the different repressive policies) that can be practised to reduce the total of the so called rate. Finally, some reasons are noted in pro of the prevention systems which Calabresi called "specific"; specially those that restrain the exercise of potential dangerous activities to previous authorization or control.

Keywords: economic analysis of the law, Calabresi, Stigler, Becker. 


\section{Dedicatoria}

Entre las muchas virtudes del profesor GARZÓN VALDÉS, ninguna brilla con más intensidad que su contagiosa curiosidad. No bay muchas personas que cumplan como él con el adagio clásico de que nada de lo bumano debe sernos ajeno. Su curiosidad sin límites, como buen filósofo, lo abarca todo o casi todo. Sus escritos y traducciones -éstas con particular evidencia- lo demuestran cumplidamente. Espero que esta paráfrasis, con dos pequeñas variaciones - hilvanadas con poco éxitode un trabajo boy ya clásico, generado extramuros de nuestra ciencia, no merezca totalmente su desaprobación.

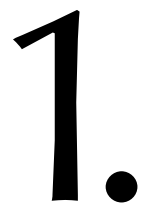

No debería sorprendernos la frecuencia con que en la vida diaria se violan las leyes. Los economistas conocen bien las causas que explican la persistencia del crimen, el fraude y el delito. Nuestras aspiraciones y deseos van por delante de nuestros ingresos o recursos. Es por ello que, siempre que las ganancias esperadas superen las previsibles pérdidas, las metas u objetivos ilegales, por inmorales que puedan parecernos, nunca dejarán de ser perseguidas.

Dicho de otro modo. El montante de las pérdidas que soportan las actividades ilegales (y, por tanto, su carestía) depende de los esfuerzos que hacen los Estados para perseguirlas. Ahora bien, como las políticas de prevención y castigo generan costes, esos costes suben progresivamente a medida que crecen los esfuerzos de los Estados y como los recursos públicos son limitados, el fraude y el delito nunca podrán ser completamente suprimidos.

2. La lucha contra las actividades ilegales, por lo demás, se complica cuando, como pasa en muchos casos, las infracciones cometidas no generan víctimas, son éstas difusas o difícilmente identificables —o los eventuales daños que puedan producir sólo pueden valuarse con muchas dificultades.

La falta de víctimas —o al menos de víctimas conocidas- complica evidentemente las cosas. Las víctimas, porque deben ser compensadas, tienen interés en que se descubra a los culpables y, por ello, su presencia facilita, contribuye eficazmente, a su detención y castigo.

Las actividades ilegales o criminales, sin embargo, cuando faltan víctimas, no tienen por qué rendir siempre forzosamente más beneficios. Más bien sucede lo contrario. La amenaza de sanciones siempre retrae a posibles competidores de modo que, al final, se produce la extraña o curiosa paradoja, de que cuanto más eficaz es una prohibición, más atractiva económicamente se vuelve la actividad prohibida.

3. Se entiende ahora por qué, cuanto más perseguida esté una actividad ilegal, más peligrosos se vuelven quienes la realizan —o se benefician o viven de ella—. No cabe abrigar duda alguna de que, cuanto más perseguida esté una actividad, más elevadas serán las ganancias esperadas, pero cuanto mayores sean las ganancias, mayores serán también los incentivos para la ejecución de las conductas prohibidas.

Estamos, en efecto, ante una especie de círculo vicioso: cuanta más represión, menos competidores y por tanto más beneficios esperados; cuanto más beneficios espera- 
dos, más atractiva se vuelve la actividad ilegal; cuanta más atractiva sea la actividad, mayor será el interés en realizarla; pero, cuanto mayor sea el interés, más difícil se volverá la aplicación de la ley.

4. También se explica ahora por qué no se persigue a todos los criminales con la misma intensidad. Precisamente porque la aplicación de la ley siempre es costosa, no todas las actividades prohibidas son perseguidas por el Estado o la sociedad con el mismo ahínco.

La aplicación de la ley hay que pagarla y, por ello, aun cuando los fines perseguidos puedan parecer igualmente valiosos, habrá diferencias en la intensidad de la represión aplicada siempre que el coste de su ejecución no sea, en cada caso, el mismo.

5. No sólo eso. La eficacia de las políticas represivas depende de más cosas que de la magnitud del esfuerzo comprometido por los Estados en la prevención y castigo de las conductas prohibidas. Existen otros factores que también juegan un importante papel:

i) En primer lugar, importa la relación que sin duda existe entre la varianza en los beneficios que pueden obtener los infractores por su conducta y la de los agentes públicos en sus retribuciones por hacer que las leyes se cumplan. Es un hecho fácilmente comprobable que el rigor en la aplicación de las leyes disminuye a medida que aumentan las ganancias de los malhechores. Los pequeños rateros, por ejemplo, suelen ser apresados con mucha más facilidad que los grandes delincuentes económicos o los criminales de cuello blanco.

ii) En segundo lugar, importa también la frecuencia con que los posibles criminales o malhechores entran en contacto con los agentes encargados de vigilarlos. La repetición habitual de la conducta transgresora — sobre todo cuando los beneficios a repartir son sustanciosos-facilita la colusión entre agentes públicos y delincuentes y, por tanto, la aparición de formas más o menos encubiertas de cohecho.

6. La repetición de los contactos, en efecto, multiplica las posibilidades de entablar negociaciones y, en consecuencia, de conseguir un trato de favor de Tribunales, inspectores y policías a cambio de las oportunas contraprestaciones que pueden ir desde pequeñas compensaciones por hacer la «vista gorda» hasta sobornos en toda regla.

Todo ello permite explicar por qué los delincuentes habituales y violadores sistemáticos de la ley tienen tendencia a organizarse. No cabe duda de que la facilidad de las organizaciones delictivas para establecer relaciones «provechosas» de colaboración con los agentes de la ley es muy superior que la que puedan tener, por separado, cada uno de sus afiliados.

7. En resumen, tanto mayor será la tendencia a la colusión entre los malhechores y sus vigilantes cuanto más elevados sean los beneficios esperados de la actividad prohibida.

Esta propensión se mantiene incluso aunque las infracciones generen víctimas perfectamente identificables; y se mantiene o acentúa porque — como los demandantes de ilegalidad a los agentes públicos son pocos y están organizados (constituyen casi verdaderos «monopsomios»); y, en cambio, los demandantes de legalidad, por las características de este tipo de «mercado», suelen ser muchos y están desorganizados, con casi 
toda seguridad saldrán perdedores estos últimos en la puja entablada para conseguir unos e impedir otros la aplicación de las leyes represivas del Estado.

8. La causa está en que, a medida que disminuye el número de presuntos defraudadores, incrementan las posibilidades de colusión o contacto y disminuyen las posibilidades de detección. Ahora bien, siempre que decrezca el éxito de la detección; subirán inmediatamente los márgenes del negocio y, por tanto, también la capacidad de su titular para llegar a acuerdos ventajosos con los agentes o servidores del Estado.

Se entiende por que, con este panorama y bajo estas condiciones, parece poco recomendable permitir o dejar que los vigilantes de la ley puedan negociar directamente con los posibles transgresores (como pasa ya en el ámbito fiscal). No es ésta, sin embargo, la única razón que juega en contra: hay alguna más.

9. En principio podría parecer indiferente que, quien cobre la condena o pena establecida, sea el Estado o su agente ya que la eficacia de la restricción sobre la conducta probibida, siempre que la cantidad pagada sea la misma, es idéntica en ambos casos. Lo que no quiere decir otra cosa que, en principio, no parecen existir obstáculos para que la organización de la represión del fraude y el delito pueda dejarse en manos del mercado.

En efecto, si el montante del soborno y de la sanción son equivalentes o iguales, los efectos disuasorios serán también forzosamente los mismos. Hay sin embargo excepciones que impiden una aplicación general de esa regla:

i) No será indiferente nunca si es el caso que existen víctimas, porque —al embolsarse toda la cantidad abonada por el culpable el agente sobornado— no se pagará a los perjudicados la totalidad de los daños sufridos.

ii) Pero tampoco es indiferente cuando — aún faltando víctimas identificablesla cantidad abonada al agente por el malhechor sea inferior a la cuantía de la pena que debía soportar; en estos casos el cohecho o soborno reducen la sanción - $\mathrm{y}$, de paso, su eficacia o poder disuasorio - con lo que la sociedad en su conjunto soportará una pérdida neta.

10. Así las cosas todo se reduce a identificar aquellas situaciones en que la cuantía del soborno tiende a ser inferior a la de la pena o sanción que corresponde según ley.

Hay al menos uno en que tal consecuencia parece inevitable. Será, sin duda, inferior el pago al agente (con los correspondientes costes sociales por sobre-actividad infractora) cuando la competencia entre los guardianes de la ley rebaje el precio de su «colaboración» para que puedan prosperar los «negocios» de delincuentes y malhechores.

La negociación libre con los vigilantes, en estos casos, no sólo facilita el contacto repetido con los transgresores - y por tanto incrementa el peligro de que se establezcan acuerdos para burlar la ley — sino que, a causa de la estructura «oligopsómica» del mercado, forzará que los precios de esos acuerdos tiendan a la baja.

11. Así las cosas, parece que, en estas condiciones, de permitir a alguien negociar con los vigilantes de la ley, sólo debería permitirse a las potenciales víctimas. A nadie puede ocultársele, sin embargo, que esta completa inversión de la concesión del derecho a negociar (antes a los infractores, ahora a sus víctimas) supone una total y completa inversión del papel y función de los incentivos (y por tanto de la política represiva). 
Lo que se trata de saber (y decidir) es si los efectos de esa inversión son positivos $y$, a lo que parece, todo inclina a pensarlo así. En efecto, el reconocimiento del derecho de negociar (y por tanto a elegir vigilante) sólo y exclusivamente a las víctimas,

i) Por una parte, promociona la colusión entre éstas y los vigilantes (lo que no perjudica el interés público sino, al contrario, como veremos, lo garantiza).

ii) Y, por otra, dificulta los acuerdos entre los vigilantes y los malhechores (lo que, como hemos visto, redunda en beneficio del interés general).

12. Por razones obvias existe una generalizada confianza en todas partes en que las víctimas, en su propio interés, tienen siempre la firme voluntad de que se cumplan las leyes.

No cabe duda de que, si se dejase en sus manos la persecución de los infractores y se les garantizase la indemnización de todos los daños, la cantidad de aplicación de la ley sería óptima (como pasa por ejemplo con el robo en almacenes o tiendas): estaríamos ante una especie de fiscales incorruptibles.

La mayoría de las víctimas, sin embargo, no tienen interés en transformarse en vigilantes directos del cumplimiento de las leyes porque el éxito en las tareas de investigación, acusación y condena de los presuntos culpables, exige la posesión de conocimientos especializados que, en la mayor parte de los casos, no son fáciles de adquirir.

13. Ahora bien, de lo que no cabe duda es que, si las víctimas tienen un indiscutible interés en que se les reparen los perjuicios sufridos, estimularán la aparición de eficaces guardianes de la ley que se dediquen profesionalmente a garantizar que ésta se cumplirá, que se encontrará a los culpables de burlarla y que se les castigará por las infracciones que hayan cometido.

Por lo demás, también aquí los acuerdos a que puedan llegar las víctimas y sus agentes no podrán versar sobre otra cosa que sobre el sistema de reparto de las penas e indemnizaciones, debidas por los culpables, que habría que distribuir (una vez reparados los daños producidos) en función del esfuerzo empeñado por cada parte (víctimas e investigadores) en la busca e identificación de los culpables. En consecuencia, como toda investigación tiene siempre un coste, el montante de las sanciones impuestas a los infractores (y por tanto la base del reparto) debe superar la cuantía de la compensaciones que corresponde pagar a las víctimas por los daños sufridos.

14. En la práctica, sin embargo este modelo (del «cazarrecompensas»), tan fascinante por su sencillez, no cuenta hoy con muchos seguidores. Hay razones poderosas que explican el rechazo. Así, por ejemplo, siempre que se persiga no tanto la represión del fraude como su prevención; es decir, cuando interesa la aplicación ex ante, no ex post, de la ley.

i) Primero, porque, en estos casos, siempre que no lleguen a consumarse los delitos o fraudes a causa del esfuerzo en prevención del agente o vigilante, faltarán los incentivos para investigar ya que no habrá indemnización que cobrar ni, por tanto, recompensa alguna que repartir.

ii) Segundo, porque siendo por hipótesis preventivo el control, no habrá víctimas efectivas sino sólo potenciales; lo que hará disminuir mucho el interés de cada miembro del grupo de riesgo en contratar y pagar los servicios de control o vigilancia (todos 
tenemos dificultades para valorar adecuadamente la gravedad e importancia de los peligros de carácter colectivo y naturaleza futura o eventual).

iii) Tercero, porque las potenciales víctimas - puestas a elegir entre un coste actual y el riesgo de una pérdida futura, aunque sea grande- suelen inclinarse por esta última ya que, como es sabido, las desgracias siempre les ocurren, con más frecuencia, a los demás (complejo de «Fausto»).

15. No otra debe ser la conclusión cuando nos encontramos ante delitos o infracciones sin víctimas. Muchas de entre las variadas infracciones que se cometen todos los días carecen de víctimas conocidas, es decir, de víctimas identificables ni siquiera grosso modo (piénsese en la legislación de protección de las costas o el medio ambiente).

En estas condiciones, las dificultades para la negociación del acuerdo entre las potenciales víctimas (los grupos de riesgo) y los vigilantes se disparan ya que a los peligros típicos de una situación de «monopolio bilateral o multilateral» (proliferación de gorrones que se aprovechan de la prevención pero escurren pagar sus costes) habría que sumar los de por sí elevados costes de contratación cuando los beneficiarios del servicio (y por tanto posibles afectados o interesados en el acuerdo) son muchos y por encima difíciles de identificar.

Habría, por consiguiente, con toda seguridad, si se dejase la elección del controlador (y, por tanto, la misma práctica del control) a la iniciativa de las potenciales víctimas, una manifiesta infra-inversión en prevención con los consiguientes costes para el conjunto de la sociedad (retraimiento de la demanda como consecuencia del incremento de incertidumbre sobre la eficacia de la garantía estatal de los derechos).

16. Parece, por tanto, que —en beneficio de la colectividad, además de las posibles víctimas - cuando éstas son muchas y difíciles de identificar, los Estados deben implantar controles forzosos de legalidad o sistemas públicos de prevención. Los costes de funcionamiento del servicio deben soportarlos quienes van a ver mejorada su posición como consecuencia de la implantación de las organizaciones de control.

La razón de que la mayoría de los países carguen a los grupos de riesgo con el pago de los costes está en que la prevención revaloriza sus activos al incrementar la expectativa de su uso pacífico en el futuro. En efecto, el incremento del margen de riesgo que produce una deficiente protección presiona al alza el coste del seguro, disminuye en proporción las rentas futuras y, en consecuencia, reduce el valor de capitalización de los activos.

17. Esta opción, por razones obvias, se vuelve todavía más recomendable cuando para ejercer eficazmente la prevención sea necesario poner en acción, servirse, de potestades públicas o instrumentos de coacción cuyo ejercicio, en principio, está reservado al Estado.

Debido al delicado problema que plantea siempre la delegación en particulares de poderes públicos, es conveniente reservar su gestión a organizaciones o empresas previamente autorizadas o «habilitadas» debido al peligro de incurrir en sobre actividad, gastos superfluos (duplicación de actuaciones) o, lo que es peor, de adoptar medidas (represivas) incompatibles o contradictorias.

Hay otra razón que hace aconsejable la intervención del Estado. La intervención pública se vuelve necesaria para garantizar adecuadamente la solvencia de los agentes 
responsables, debido a los cuantiosos daños (públicos y privados) que pueden ocasionar sus decisiones erróneas.

18. Ciertamente, si eliminamos la competencia entre los agentes, careceremos de una orientación segura sobre el gasto total óptimo en aplicación de la ley que debemos afrontar. Lo que sin duda constituye un defecto importante o grave pero no decisivo. Hemos visto un poco más atrás como en este punto las soluciones de mercado tampoco ofrecen muchas garantías.

Lo que sí, en cambio, estaríamos en condiciones de calcular, es cuál debe ser la retribución óptima de cada vigilante, juez o controlador. En principio, como los costes de investigación de las irregularidades en la ejecución de la ley son altos (ya que los mismos vigilantes tratarán por todos los medios de obstaculizar su detección) será necesario incrementar, para garantizar una eficaz ejecución de las leyes, las penas que hay que imponer a los inspectores en el caso de que incumplan sus funciones.

Una de las fórmulas ensayadas con notable éxito es la que propone pagar a los agentes algo más de lo que cobrarían en trabajos alternativos (es decir, con preparación, riesgo y esfuerzos similares) para, al mismo tiempo, amenazarles con el despido fulminante, incluso, por pequeñas o incluso insignificantes irregularidades.

19. La determinación de ese sobresueldo o prima no parece imposible. Según el modelo STIGLER-BECKER, estará en relación directa con los beneficios (procedentes de la corrupción) que puedan obtener los agentes públicos y en relación inversa con la probabilidad de detección (y por tanto castigo) de las irregularidades cometidas.

En concreto, cuanto más alto pueda ser el beneficio del agente corrupto (que esté dispuesto a pagar el infractor) y menor la posibilidad de detección, mayor sería la diferencia entre el sobresueldo y la mejor alternativa salarial que nuestro vigilante o agente está en condiciones de encontrar en el mercado.

Esta debería ser, pues, para un operador racional, la medida de la «tentación de la corrupción», y por tanto el precio a pagar por aquellos que desempeñan su oficio de forma incorrecta o negligente. El coste del despido (la pena con que se amenaza al agente poco escrupuloso) en el caso que se llegase a descubrir el cohecho, o su desidia o falta de interés, sería equivalente, por tanto, al valor del flujo de renta futura que dejaría de percibir.

\section{BIBLIOGRAFÍA UTILIZADA}

El trabajo clásico a que se hace referencia en la dedicatoria es evidentemente el de BECKER, G., y STIGLER, G., 1997: La aplicación de las leyes, la corrupción y la remuneración de los jueces, accesible en español, en FEBRERO-SCHWARTZ (recs.), La esencia de Becker, p. 503. La paráfrasis ocupa la primera mitad del presente escrito. Las variaciones, que después se permite, buscan amparo en la autoridad de CALABRESSI, G., 1984: El coste de los accidentes (Análisis económico y jurídico de la reponsabilidad civil), pp. 107 y ss.

Es curioso que la moderna economía institucional haya resucitado viejas antítesis metafísicas o filosófico morales. La hipótesis de «racionalidad limitada», por ejemplo, no parece más que una toma de posición en la discusión tradicional sobre finitud/infinitud y precisamente a favor de la superioridad de la vida sobre el conocimiento (en Historia, de la llamada desde S. AGUS- 
TíN «heterogonía de las intenciones»). La inevitabilidad de los «costes de agencia», por su parte, sería una simple traducción al plano económico - y, por tanto, una prueba irrefutable- de la maldad de la naturaleza humana. La «tragedia de los comunes», por último, una derivada posterior de la misma premisa y por tanto del bellum omnium.

A lo que parece, quedan todavía muchos mediterráneos por descubrir. Sobre los costes de agencia, que es de lo que trata el presente escrito, es referencia obligada: FAMA, E., 1980: «Agency Problems and the Theory of the Firm», en JPE, 88: 288-307. Para las cuasi-rentas, KLEIN, B.; CRAWFORD, R., y AlCHIAN, A., 1978: «Vertical Integration, Apropiable Rents and Competitive Contranting Process», en JLE, 21: 297-326.

Sobre garantías de «calidad», y las dificultades para conseguirla —el otro motivo del escrito- disponible ahora en italiano: AKERLOF, G., 2003: «Il mercato dei "Bidoni": la incertezza della qualità e il meccanismo di mercato», en Racconti di un nobel dell Economía. Asimitria informativa e vita quotidiana, pp. 7 y ss. Y sobre todo, siempre agudo: BARZEL, Y., 1987: «The Entrepreneur's Reward for self-Policing», en EI, 25: 103-116. 